\title{
Importância do Capital Intelectual em uma Instituição de Ensino Superior
}

\section{The Importance of Intellectual Capital in an Higher Education Institution}

\author{
MARLLA DE OLIVEIRA FEITOSA (D) \\ WALID ABBAS EL-AOUAR ID \\ ARTHUR WILLIAM PEREIRA DA SILVA (D) \\ HELAINE CRISTINE CARNEIRO DOS SANTOS D \\ ANA LÚCIA DE ARAÚJO LIMA COELHOD
}

\section{RESUMO}

A gestão da informação e do conhecimento que resultam na formação do capital intelectual tem se apresentado como estratégias fundamentais para organizações que anseiam sucesso, tendo em vista que a partir do gerenciamento dos ativos intangíveis e da compreensão de capital estrutural, capital do cliente e capital humano, torna-se possível desenvolver estratégias competitivas no cenário em que a organização está inserida. O objetivo deste estudo foi investigar a importância atribuída aos ativos intangíveis críticos para avaliação do Capital Intelectual de cursos de Graduação em uma Instituição de Ensino Superior brasileira. Trata-se de um estudo de caso com finalidade descritiva. A pesquisa foi direcionada a quatro coordenadores de cursos de graduação da Instituição em que foi aplicado o instrumento de coleta de dados. O banco de dados foi construído em formato Excel, para elaboração das tabelas descritivas e aplicação do teste estatístico de Kruskal Wallis. Constatou-se a importância atribuída aos ativos intangíveis críticos em todas as dimensões do processo avaliativo. No entanto, falta o gerenciamento destes de forma eficiente, refletindo na composição do capital intelectual da Instituição. Percebeu-se que as coordenações não gerenciam 
de forma estratégica os ativos intangíveis existentes, impactando seu capital intelectual.

Palavras-chave: Informação. Conhecimento. Ativos intangíveis. Gestão. Vantagem competitiva.

\section{ABstract}

Intellectual capital has been demonstrating to be a fundamental strategy for organizations that desire success, taking into account that from the management of intangible assets and the understanding of structural capital, customer capital and human capital, making it possible to develop competitive strategies in the setting in which an organization operates. This paper aims to investigate the importance attributed to the critical intangible assets for the evaluation of Intellectual Capital of undergraduate courses in an Institution of Higher Education Brazilian. This is a case study with descriptive purpose. The research was endeavored to four coordinators of undergraduate courses of the Institution in which the instrument of data collection was applied. The database was elaborated in Excel format, for the accomplishment of the descriptive tables and application of the statistical test of Kruskal Wallis. The importance attributed to critical intangible assets was verified in all dimensions of the evaluation process. However, management of this sort in an efficient manner is lacking, reflecting in the composition of the Institution's intellectual capital. It was noticed that the academic departments did not strategically manage the existing intangible assets, which directly implies in the development of the institution's intellectual capital.

Key words: Information. Knowledge. Intangible assets. Management. Competitive advantage.

\section{INTRODUÇÃo}

A gestão do capital intelectual - CI vem se concretizando como um meio crítico de sucesso para criação de vantagens competitivas nas organizações (NADEEM; GAN; NGUYEN, 2018; NOVGORODOV, 2018; SARDO; SERRASQUEIRO; ALVES, 2018;). Stewart (1998) e Novgorodov (2018) compreende-o como um conjunto de conhecimentos e informações que agreguem valor às organizações mediante a utilização de ativos intangíveis, sobrepondo-se aos ativos 
tangíveis. Edvinsson e Malone (1998) e Sardo, Serrasqueiro e Alves (2018) como a lacuna existente entre o valor de mercado e o valor contábil de uma organização.

Nessa nova sociedade, os valores atribuídos aos ativos físicos representam apenas uma parcela do quanto vale, em termos monetários, a organização (NEVES et al., 2018). O CI pode ser confundido como a raiz de uma árvore; as pessoas de fora visualizam apenas os produtos e serviços, entretanto, o valor discorre de algo a mais. Os meios e processos, investimentos em qualificação profissional, ambientes favoráveis ao compartilhamento de conhecimentos e inovações tecnológicas, são aquisições necessárias para o alcance dos resultados almejados (NEVES et al., 2018; EDVINSSON; MALONE, 1998).

As mudanças ocorridas na estrutura e no gerenciamento dos ativos não são indispensáveis apenas em empresas que comercializam produtos tangíveis. As Instituições de Ensino Superior - IES vêm exigindo cada dia mais práticas consolidadas que estabeleçam o gerenciamento eficaz dos ativos disponíveis (AL-HEMYARI; AL-SARMI, 2018; BRATIANU, 2018; CRICELLI et al., 2018; NDOU et al., 2018). Daí a necessidade de registro, mensuração e controle dos ativos intangíveis.

O material intelectual pode ser entendido como uma combinação entre conhecimento, informação, propriedade intelectual e experiência, de modo que o gerenciamento destes ativos crie valor. O gerenciamento deste ativo divide-se em três dimensões: capital humano, relacional e estrutural (NOVGORODOV, 2018; SARDO; SERRASQUEIRO; ALVES, 2018; BRATIANU, 2018; CRICELLI et al., 2018; VASCONCELOS; CASTRO; BRITO, 2018; BRITO; OLIVEIRA; CASTRO, 2012; STEWART ,1998).

Para Nadeem, Gan e Nguyen (2018) e Cricelli et al. (2018) a mensuração do CI é vantajosa pelas informações que são disponibilizadas, capazes de alimentar sistemas de informações disponíveis, e contribuir para que os gestores verifiquem as receitas geradas por estes e tomem as decisões, no que concerne aos funcionários, clientes e fornecedores. Stewart (1998) e Castro, Brito e Varela (2017) inferem ainda à gestão do $\mathrm{CI}$, como a capacidade de aprender a aprender.

Assim, as organizações intensivas em conhecimento devem favorecer o compartilhamento deste, se socializando com outros meios acadêmicos ou institucionais. 
A expansão do mercado educacional trouxe consigo consequências como a concorrência acirrada, exigindo dos gestores o aperfeiçoamento contínuo em modelo administrativo. A importância apresentada ao gerenciamento do CI para IES é conferida pela necessidade dela buscar estabelecer, de forma contínua, a criação de ambientes favoráveis à disseminação e compartilhamento de conhecimento, estabelecendo contato com o meio acadêmico e outras organizações, com o intuito de atingir seus resultados e favorecer o desenvolvimento regional, mediante a educação (AL-HEMYARI; AL-SARMI, 2018; BRATIANU, 2018; CRICELLI et al., 2018; NDOU et al., 2018; NOVGORODOV, 2018; SANTOS ET AL., 2017).

Compreendendo da importância do CI para a sobrevivência e desenvolvimento das organizações (NADEEM; GAN; NGUYEN, 2018; NOVGORODOV, 2018; SARDO; SERRASQUEIRO; ALVES, 2018), surge o objetivo deste artigo: Investigar a importância atribuída aos ativos intangíveis críticos para avaliação do Capital Intelectual de cursos de graduação em uma Instituição de Ensino Superior da cidade de Cajazeiras-PB.

\section{REFERENCIAL TEÓRICO}

\subsection{Conceituação de Capital Intelectual}

As tentativas de se definir o CI são inúmeras, e diversos pensadores têm discorrido a respeito desse tema. Embora haja discordâncias em alguns aspectos, os conceitos apresentam fundamentalmente o mesmo teor. Rezende afirma que:

O Capital Intelectual é o capital que reside na cabeça das pessoas, proveniente do trabalho e criação do intelecto e, no contexto da empresa, é a experiência acumulada pelo esforço de pesquisa de novos produtos e métodos de trabalho, pelo desenvolvimento e domínio de tecnologias emergentes e aprimoramento das relações e parcerias (REZENDE, 2002, p. 78).

Sardo, Serrasqueiro e Alves (2018) e Nadeem, Gan e Nguyen (2018) corrobram o conceito de Rezende (2002) ao argumentarem que o CI inclui, além do intelecto humano, a tecnologia investida 
na empresa e a capacidade das pessoas em usarem a criatividade e experiência para criar novos produtos e serviços, utilizando as ferramentas tecnológicas, além de inovarem os métodos de trabalho para atingir a eficiência no ambiente organizacional. Essa concepção encontra respaldo na definição de Brooking (1996, p. 12): o “Capital Intelectual atua como uma combinação de ativos intangíveis, frutos das mudanças na área de tecnologia da informação, mídia e comunicação, que trazem benefícios intangíveis para as empresas e que capacitam seu funcionamento". Para Brooking (1996), e outros autores como Ndou et al. (2018) e Neves et al. (2018) o CI é dividido em quatro grupos: a) ativos de mercado, tais como: marcas e franquias; b) ativos humanos, como: criatividade, conhecimento, habilidade para resolver problemas, entre outros; c) ativos de propriedade intelectual, como: know-how, patentes, designs, segredos industriais; e, d) os ativos de infraestrutura, tais como: tecnologias, sistemas de informação, banco de dados de clientes etc.

Novgorodov (2018), Vasconcelos, Castro e Brito (2018) e Stewart (1998) compartilham o entendimento do CI como um conjunto de conhecimentos e informações que agreguem valor às organizações, mediante a utilização de ativos intangíveis, sobrepondo-se aos ativos tangíveis.

O CI é caracterizado por não possuir existência física, ser volátil, não haver garantia de sua estabilidade dentro das empresas, e sua identificação e mensuração serem complexas, podendo se manifestar em forma de pesquisas, livros, relatórios, conhecimento, etc (NADEEM; GAN; NGUYEN, 2018; NOVGORODOV, 2018; BRITO; OLIVEIRA; CASTRO, 2012).

Dessa forma, o CI vem sendo interpretado como o reconhecimento dos ativos incorpóreos, ou intangíveis, que acrescentem valor à organização, sendo estes reconhecidos pela contabilidade ou não. (NEVES et al., 2018; SARDO; SERRASQUEIRO; ALVES, 2018; VASCONCELOS; CASTRO; BRITO, 2018; NADEEM; GAN; NGUYEN, 2018; NOVGORODOV, 2018; BRITO; OLIVEIRA; CASTRO, 2012; SANTOS et al., 2017).

O capital humano compreende todas as habilidades e competências inerentes às pessoas que geram benefícios às organizações as quais pertencem, e nasce a partir da valorização dos indivíduos 
quando vistos como ativos. Para Sardo, Serrasqueiro e Alves (2018) e Stewart (1998) o capital humano é a fonte de inovação, onde as ideias são livres e abundantes e, provavelmente, infinitas. Assim, pode ser considerado como um recurso ilimitado que aumenta à medida que a entidade utiliza o conhecimento adquirido pelas pessoas, promovendo sua multiplicação. Porém, a empresa não tem como garantir a sua permanência, pois se um funcionário se desligar dela, levará consigo todo o conhecimento adquirido.

De acordo com Nadeem, Gan e Nguyen (2018) o capital estrutural se refere ao conhecimento que pertence à empresa, e estão incluídos: tecnologia, estrutura, sistemas de informações e bancos de dados, além de aspectos relacionados à cultura e aos processos organizacionais. Pode-se dizer que ocorre a transformação do conhecimento individual em patrimônio por meio da troca de experiências e do poder de inovação.

Para Marques (2009, p. 29) “o capital estrutural é um conjunto de conhecimentos e ativos intangíveis resultantes de processos de ação que são propriedade da organização e que ficam na organização quando as pessoas a abandonam". É a base para o capital humano, ou seja, o alicerce para que as pessoas exerçam suas atividades.

Neves et al. (2018) afirma que o capital do cliente, ou de relacionamento, trata-se do conhecimento incorporado através das relações e alianças entre a empresa e seus clientes e fornecedores. Para Stewart:

O capital do cliente é muito semelhante ao capital humano: não se pode possuir os clientes do mesmo modo como não se pode possuir pessoas. Mas da mesma forma como uma organização pode investir em funcionários não apenas para aumentar seu valor como indivíduos, mas também para criar ativos de conhecimento para a empresa como um todo. A empresa e seus clientes podem aumentar o Capital Intelectual que é sua propriedade em conjunto e em particular (STEWART, 1998, p. 138).

Considera-se, portanto, o capital de relacionamento como àquele que garante a continuidade das atividades da empresa. Assim, faz-se necessário que ela mantenha uma parceria cada vez melhor com seus clientes, de forma a conquistá-los e mantê-los sempre próximos. 


\subsection{Capital Intelectual nas IES}

Compreendendo-se a importância do conhecimento e das informações como fontes geradoras de sucesso em IES, às quais apresentam como principais ativos corpo docente e funcionários, responsáveis pela disseminação de conhecimento entre discentes e sociedade, autores como (AL-HEMYARI; AL-SARMI, 2018; BRATIANU, 2018; CRICELLI et al., 2018; NDOU et al., 2018; NOVGORODOV, 2018; SANTOS et al., 2017; BODNÁR et al., 2010) expõem a preocupação de muitos pesquisadores sobre a valorização dos ativos intangíveis nestas organizações.

Al-hemyari e Al-sarmi (2018), Bratianu (2018) e Cricelli et al. (2018) entendendo que as IES negociam conhecimento, argumentam que os gestores devem preocupar-se com seu desempenho e sua conquista de espaço no mercado, faz-se necessário o controle contínuo de seus ativos intangíveis para criação de valor.

O corpo docente das instituições carece de constantes atualizações e investimento em estudos e pesquisas, favorecendo a construção e ampliação do conhecimento de seus clientes (discentes), e contribuindo com a comunidade em geral. Ndou et al. (2018), Novgorodov (2018) e SANTOS et al. (2017) afirmam que apesar da organização sobreviver do gerenciamento de competências, habilidades, inteligência e saberes dos professores, ainda não se observam facilmente iniciativas em mensurar, registrar e controlar estes ativos.

Al-hemyari e Al-sarmi (2018) e Ndou et al. (2018) ressaltam ainda que embora a literatura trate com maior respaldo a valorização destes ativos para organizações industriais, o estudo do CI em IES vem crescendo significativamente.

\subsection{Modelo de Avaliação de CI Adotado Neste Estudo}

Há diversos modelos de avaliação de CI (CRICELLI et al., 2018; NDOU et al., 2018; NEVES et al., 2018; NOVGORODOV, 2018). Utilizou-se neste estudo o de Dumay (2009b), devido a sua maior adequação à realidade das IES brasileiras.

Dumay (2009b) avaliou a importância do CI em cursos de MPA, de IES brasileiras, reconhecidos pela CAPES, através de pesquisa com professores e coordenadores, onde identificou-se a necessidade de elaborar um modelo válido, que foi adotado nesta pesquisa, e se 
divide em três seções: Plano Estratégico, Ativos Intangíveis Críticos e Indicadores de CI, separados em dimensões: Capital Estrutural, Capital Relacional e Capital Humano. O modelo foi estruturado a partir de um estudo sobre as principais técnicas de avaliação do CI em IES no Brasil e no mundo, tendo sido obtido como principais referências dois modelos de avaliação: Demonstração de CI utilizado pelas universidades austríacas; Demonstração de CI das universidades, esse último modificado pelo autor a fim de viabilizar uma identidade mais aproximada das IES brasileiras.

Dumay (2009b) descreveu todo o processo efetuado na criação do seu modelo para identificar os principais ativos intangíveis críticos dos cursos de MPA, e a elaboração de indicadores que viabilizassem a análise dos recursos intangíveis, das atividades intangíveis e dos resultados de cada dimensão do CI dos cursos.

O modelo foi efetuado mediante uma pesquisa de campo com 101 professores e coordenadores de diversos cursos de MPA do Brasil, no sentido de validar os indicadores, conforme as opiniões dos entrevistados. A pesquisa foi submetida a analise fatorial exploratória, e testes para a comparação de médias para amostras independentes, e teste de independência entre variáveis categóricas, obtendo a confirmação e a validação dos indicadores e sua estrutura final.

Na primeira seção cada gestor discorreu sobre o plano estratégico do curso, estabelecendo suas metas e objetivos, e descrevendo qual o caminho percorrido. É uma etapa reconhecida por grandes autores (SÁNCHEZ; CHAMINADE; OLEA, 2000; LEITNER, 2004; KOCH, LEITNER; BORNEMANN, 2000; MARR; GRAY; NEELY, 2003; MOURITSEN, 2003) como uma das principais na avaliação do CI.

A segunda seção teve como propósito a elaboração de uma lista de ativos intangíveis que justificassem a inserção dos principais ativos, e como foram desenvolvidas as atividades que aumentam o valor destes recursos e geram CI dos cursos. O objetivo foi estabelecer uma conexão entre estes ativos e o planejamento estratégico da organização.

A terceira seção propôs a criação de indicadores, atribuindo valores de 0 a 100 para medir a importância ou não, na visão dos gestores, aos atributos ligados ao CI. 


\section{Procedimentos Metodológicos}

\subsection{Tipologia e Sujeitos da Pesquisa}

A pesquisa assumiu caráter descritivo, pois, conforme Cervo, Bervian e Silva (2007), esta acontece quando se registram, analisam e correlacionam fatos ou fenômenos, sem manipulá-los, muito embora não tenha o compromisso de explicar os fenômenos que descreve, embora sirva de base para tal (VERGARA, 2014).

Caracteriza-se ainda como um estudo de caso, pelo interesse em se conhecer a realidade de uma IES de Cajazeiras-PB. Conforme Gil (2008), uma pesquisa é classificada como estudo de caso quando procura conhecer, através de uma ferramenta de diagnóstico, como o conhecimento é captado, criado, usado, armazenado etc.

Os sujeitos da pesquisa foram os coordenadores dos cursos de graduação ofertados pela IES estudada (Ciências Contábeis, Direito, Filosofia e Serviço Social).

\subsection{Coleta de Dados}

A pesquisa ocorreu por meio de entrevistas semiestruturadas, no segundo semestre do ano de 2017, quando foi aplicado o instrumento proposto por Dumay (2009b). A coleta de dados consistiu nos seguintes passos: a) aplicação de um pré-teste junto a cinco gestores de diferentes instituições, e que conheciam o objetivo da pesquisa; e b) análise dos dados obtidos através do pré-teste, onde foi possível identificar falhas no instrumento de coleta devido à extensão do questionário.

Concluída a fase do pré-teste, a pesquisadora deu início à coleta de dados, seguindo as seguintes etapas: a) agendamento de dia e horário junto às coordenações para aplicação do instrumento; b) aplicação do instrumento de coleta de dados, a partir de entrevista individual e presencial; e, c) organização dos dados.

\subsection{Instrumento de Pesquisa}

O instrumento de coleta de dados foi o questionário desenvolvido por Dumay (2009b), que foi construído com o objetivo de avaliação do CI em cursos de Mestrado Profissional. Entretanto, nas 
sugestões finais, Dumay (2009b) discorreu sobre a aplicabilidade do questionário em cursos de graduação ou pós-graduação.

O modelo adaptado à pesquisa se divide em três seções: apresentação do planejamento estratégico dos cursos; indicação dos ativos intangíveis críticos, estimando uma análise individualizada e comparativa, possibilitando a construção de indicadores intracursos; construção e a elaboração de 43 indicadores, que possibilitam a análise comparativa entre cursos.

Devido aos resultados apresentados pelo pré-teste, a pesquisadora aplicou aos respondentes apenas a terceira seção do modelo, que consiste na construção de indicadores que avaliam as dimensões: capital estrutural, humano e capital do cliente.

Os ativos intangíveis críticos, que compõem a dimensão capital estrutural, apresentam-se pelos indicadores gestão e controle, pesquisa e produção intelectual, e infraestrutura. Os indicadores que avaliam a dimensão capital do cliente são: o programa, cooperação com instituições acadêmicas e não acadêmicas, internacionalização, e relacionamento com a comunidade acadêmica e não acadêmica. A terceira dimensão, capital humano, foi analisada através dos indicadores: docentes, pessoal administrativo e coordenadores.

O modelo avalia a importância atribuída aos indicadores que compõem o somatório do CI. Os respondentes avaliaram cada um dos indicadores sob dois aspectos: a) a importância para a avaliação de cada um dos ativos intangíveis selecionados, atribuindo um valor de 0 a 100; e, b) a dificuldade para a coleta dos dados necessários para a elaboração desses indicadores e apresentação de seus resultados no modelo simultaneamente. Foi atribuído um valor de 0 a 100. Os indicadores foram expostos através da construção de tabelas, onde ao final foram apresentadas as médias obtidas, com os valores atribuídos pelas coordenações por curso, e uma média geral, conferida à IES.

A pontuação geral obtida por cada indicador foi considerada satisfatória quando obteve média superior a 70, e insatisfatório com uma média inferior. 


\subsection{Tratamento dos Dados}

Os dados obtidos no estudo foram tratados por meio de estatística descritiva e análise de conteúdo, no intuito de verificar a importância atribuída as dimensões do capital estrutural, do cliente e humano, e assim atingir o objetivo desta pesquisa.

O banco de dados foi construído em formato EXCEL, versão 2010, para realização das tabelas descritivas e dos gráficos. Para a aplicação dos testes estatísticos (Confiabilidade dos dados e teste de Kruskal-Wallis) utilizou-se o software Statistica SPSS, versão livre temporária. Já o software livre R, versão 2.15, foi utilizado para construção da matriz de importância e dificuldade.

\section{ApresentaÇão e ANÁlise dos resultados}

\subsection{Importância do Capital Estrutural}

A análise inicia-se com a avaliação da dimensão capital estrutural, compreendido como os investimentos realizados em ativos físicos ou corpóreos, os quais tenham a finalidade de agregar valor à empresa junto aos seus clientes. O primeiro ativo intangível crítico refere-se à avaliação de gestão e controle por curso, conforme exposto na Tabela 01.

A tabela 01 apresenta uma média satisfatória aos indicadores que apontam a relação da coordenação com os discentes, direção e pessoal administrativo. Todavia, o indicador considerado crítico na avaliação é referente ao número de docentes contratados por concurso externo e interno, e o total do orçamento sobre o qual o coordenador possui autonomia.

No que se refere à pontuação atribuída aos profissionais contratados mediante concurso, observou-se que os coordenadores não atribuíram importância alguma ao indicador. Entretanto, as coordenações afirmaram que a contratação de novos docentes ocorre mediante seleção de currículo lattes e aula prática. A seleção do capital humano é uma fase importante na construção e disseminação do conhecimento, reconhecendo esse último como essencial na composição do CI. O capital estrutural diz respeito aos investimentos em ativos físicos ou tecnológicos que sejam passíveis de agregar valor à instituição junto aos seus trabalhadores, que devem ser pessoas detentoras de conhecimento (NADEEM; GAN; NGUYEN, 2018; NOVGORODOV, 2018; EDVINSSON; MALONE, 1998; STEWART, 1998). 
Tabela 01 - Grau de importância de indicadores ligados à gestão de controle, por curso

\begin{tabular}{|c|c|c|c|c|c|}
\hline Indicadores & $\begin{array}{l}\text { Contá- } \\
\text { beis }\end{array}$ & $\begin{array}{l}\text { Direi- } \\
\text { to }\end{array}$ & $\begin{array}{l}\text { Filoso- } \\
\text { fia }\end{array}$ & $\begin{array}{l}\text { Serviço } \\
\text { Social }\end{array}$ & $\begin{array}{l}\text { Pontua- } \\
\text { ção geral }\end{array}$ \\
\hline $\begin{array}{l}\text { Frequência que os professores são avaliados } \\
\text { pela coordenação do curso }\end{array}$ & 80 & 100 & 90 & 80 & 87,5 \\
\hline $\begin{array}{l}\text { Número de docentes contratados pelo curso } \\
\text { por concurso interno ou externo/número } \\
\text { total de docentes do curso }\end{array}$ & 50 & 30 & 0 & 0 & 20 \\
\hline $\begin{array}{l}\text { Total do orçamento (R\$) do curso sobre o } \\
\text { qual o coordenador tem autonomia/total } \\
\text { do orçamento (R\$) do curso, entre janeiro } \\
\text { e dezembro do último exercício social. } \\
\text { (Desconsiderar o orçamento de folha de } \\
\text { pagamento) }\end{array}$ & 50 & 20 & 50 & 30 & 37,5 \\
\hline $\begin{array}{l}\text { Frequência que a coordenação do curso se } \\
\text { reúne com a direção da escola para discus- } \\
\text { são do planejamento e objetivos estratégi- } \\
\text { cos do curso }\end{array}$ & 100 & 100 & 100 & 100 & 100 \\
\hline $\begin{array}{l}\text { Frequência que a coordenação do curso se } \\
\text { reúne com os docentes, posicionando-os } \\
\text { acerca do planejamento, metas e objetivos } \\
\text { estratégicos do curso }\end{array}$ & 100 & 100 & 100 & 90 & 97,5 \\
\hline $\begin{array}{l}\text { Frequência que os discentes e o administra- } \\
\text { tivo são posicionados acerca dos objetivos, } \\
\text { metas e planejamento estratégico do curso }\end{array}$ & 100 & 80 & 80 & 70 & 82,5 \\
\hline Pontuação geral & 80 & 71,67 & 70 & 61,67 & 70,33 \\
\hline
\end{tabular}

Fonte: Dados da pesquisa, 2017.

Em relação à parcela do orçamento que o coordenador possui autonomia, compreende-se que o processo de ensino, pesquisa e extensão demanda sentimentos, como liberdade e autonomia dos envolvidos, anseios capazes de motivar os profissionais a desenvolverem atividades produtoras de novos conhecimentos (NEVES et al., 2018; NONAKA; TAKEUCHI, 1997).

O segundo ativo intangível que avalia a dimensão do CI está relacionado com a pesquisa e produção intelectual, exposto na tabela 02 . 
Tabela 02 - Grau de importância de indicadores ligados à pesquisa e produção intelectual, por curso

\begin{tabular}{|c|c|c|c|c|c|}
\hline Indicadores & Contábeis & Direito & Filosofia & $\begin{array}{l}\text { Ser- } \\
\text { viço } \\
\text { Social } \\
\end{array}$ & $\begin{array}{l}\text { Pon- } \\
\text { tuação } \\
\text { geral }\end{array}$ \\
\hline $\begin{array}{l}\text { Número de publicações realizadas pelo } \\
\text { curso/ número de docentes permanen- } \\
\text { tes do curso, entre janeiro e dezembro } \\
\text { do último exercício social }\end{array}$ & 100 & 100 & 100 & 80 & 72,5 \\
\hline $\begin{array}{l}\text { Número de publicações acadêmicas } \\
\text { frutos de parcerias de professores do } \\
\text { curso com autores do meio empresarial } \\
\text { ou de instituições não acadêmicas, entre } \\
\text { janeiro e dezembro do último exercício } \\
\text { social }\end{array}$ & 50 & 0 & 0 & 80 & 32,5 \\
\hline $\begin{array}{l}\text { Número de citações de trabalhos pu- } \\
\text { blicados pelos docentes do curso, entre } \\
\text { janeiro e dezembro do último exercício } \\
\text { social }\end{array}$ & 0 & 0 & 30 & 0 & 7,5 \\
\hline $\begin{array}{l}\text { Total de recursos (R\$) destinados à } \\
\text { pesquisa do curso/orçamento (R\$) total } \\
\text { do curso, entre janeiro e dezembro do } \\
\text { último exercício social }\end{array}$ & 90 & 50 & 30 & 0 & 42,5 \\
\hline $\begin{array}{l}\text { Gastos totais }(\mathrm{R} \$ \text { ) com docentes do cur- } \\
\text { so em eventos acadêmicos/número de } \\
\text { docentes permanentes do curso, entre } \\
\text { janeiro e dezembro do último exercício } \\
\text { social }\end{array}$ & 70 & 50 & 70 & 0 & 47,5 \\
\hline Pontuação geral & 64 & 22 & 50 & 32 & 40,5 \\
\hline
\end{tabular}

Fonte: Dados da pesquisa, 2017.

Considerando o indicador número de publicações efetuadas pelo curso, identificou-se que as coordenações não possuem controle sobre as publicações efetuadas, pois foi justificado que a produção intelectual é de responsabilidade do Núcleo de Extensão e Pesquisas Acadêmicas - NEPA, o que implica considerar que, se não existe o controle, as coordenações não se utilizam das produções para somar ao CI dos cursos. 
Avaliando a importância dos orçamentos destinados à pesquisa e a participação em eventos acadêmicos, identificou-se que as coordenadoras não possuem controle sobre o orçamento, pois quando os docentes precisam do auxílio profissional procuram a direção, que estabelece o orçamento a ser destinado sem nenhum envolvimento com a coordenação.

Relacionando as ações consideradas importantes com o atributo do capital estrutural, observa-se que na IES há ações conectadas à produção intelectual, entretanto faltam indicadores que as ordenem ao planejamento do curso. Al-hemyari e Al-sarmi (2018), Terra (2005) e Sveiby (1998) ressaltaram que nesta nova era, a sobrevivência das organizações provêm de ações e estratégias que desenvolvam vantagens competitivas.

A Tabela 03 evidencia os indicadores atribuídos à infraestrutura do curso.

Tabela 03 - Grau de importância de indicadores

ligados à infraestrutura, por curso

\begin{tabular}{|c|c|c|c|c|c|}
\hline Atributos & Contábeis & $\begin{array}{l}\mathrm{Di}- \\
\text { reito }\end{array}$ & $\begin{array}{l}\text { Filo- } \\
\text { sofia }\end{array}$ & $\begin{array}{l}\text { Ser- } \\
\text { viço } \\
\text { So- } \\
\text { cial }\end{array}$ & $\begin{array}{l}\text { Pon- } \\
\text { tuação } \\
\text { geral }\end{array}$ \\
\hline $\begin{array}{l}\text { Número de bases de dados eletrônicas dispo- } \\
\text { níveis para os estudantes do curso }\end{array}$ & 100 & 100 & 70 & 90 & 90 \\
\hline $\begin{array}{l}\text { Número de computadores com acesso à inter- } \\
\text { net e às bases de dados eletrônicas/número de } \\
\text { alunos que acessaram a rede nestes, entre janei- } \\
\text { ro e dezembro do último exercício social }\end{array}$ & 100 & 100 & 100 & 100 & 100 \\
\hline $\begin{array}{l}\text { Número de horas semanais em que a biblioteca } \\
\text { fica aberta }\end{array}$ & 100 & 100 & 100 & 100 & 100 \\
\hline $\begin{array}{l}\text { Investimento (em R\$) em infraestrutura nas } \\
\text { dependências do curso em administração/total } \\
\text { do orçamento (R\$) do curso, realizado entre } \\
\text { janeiro e dezembro do último exercício social }\end{array}$ & 100 & 100 & 70 & 80 & 87,5 \\
\hline $\begin{array}{l}\text { Média do número de login mensal de alunos à } \\
\text { rede interna do curso (intranet)/número total } \\
\text { de alunos do curso, entre janeiro e dezembro } \\
\text { do último exercício social }\end{array}$ & 100 & 100 & 90 & 0 & 72,5 \\
\hline Pontuação geral & 100 & 100 & 86 & 74 & 90 \\
\hline
\end{tabular}

Fonte: Dados da pesquisa, 2017. 
Apesar do alto nível de importância atribuído pelos coordenadores à infraestrutura, quando questionados sobre as bases eletrônicas disponíveis os respondentes revelaram não haver uma base específica, apenas o incentivo por parte dos docentes para que os discentes visitem e utilizem bases como a Scielo.

Percebe-se também que os ativos são direcionados ao processo de ensino, o que pode não gerar vantagem competitiva por não permitir uma geração eficaz do conhecimento. Vasconcelos, Castro e Brito (2018), Santos et al. (2017), Brito, Oliveira e Castro (2012), Nair e Prakash (2009) e Klein (1998) argumentam sobre a importância de criar e favorecer ambientes de prática, e que as organizações devem estabelecer ambientes de contínuo aprendizado, capazes de desenvolver habilidades e articular o conhecimento tácito em explícito, o que pode acontecer no meio acadêmico através da escrita.

Desta forma, identificou-se que a IES tem como prioridade os investimentos destinados à dimensão avaliada, entretanto, as ações podem não vir a contribuir com o seu CI, por ser perceptível que os gestores não se utilizam dos investimentos efetuados para criar e favorecer novos conhecimentos. A ausência de controle sobre o número de publicações efetuadas pelos docentes, bem como os investimentos destinados à qualificação profissional sem nenhum direcionamento à produção de novos conhecimentos, e a importância atribuída ao número de horas/aulas prestadas pelos docentes, permitem inferir que, como uma organização do conhecimento, pouca importância vem sendo atribuída pelos gestores à dimensão analisada.

\subsection{Importância do Capital do Cliente}

A avaliação da dimensão capital do cliente tem o objetivo de avaliar a relação estabelecida entre a IES e seus clientes. A tabela 04 mostra as contribuições dos ativos intangíveis ligados aos cursos.

A análise do indicador número de horas/aulas que o programa disponibiliza para o apoio de nivelamento, foi mensurado pela coordenação de Serviço Social como um índice de pouca importância. Dentre os cursos de nivelamento, os coordenadores apontaram o oferecimento destes: Língua Portuguesa, Metodologia Cientifica, e outros de cunho específico do curso. Neves et al. (2018), Bratianu (2018) e Stewart (1998) compreendem que as organizações devem manter uma relação de atenção e cuidado com seus clientes, justificando a importância atribuída aos cursos de nivelamento. 
Tabela 04 - Grau de importância de indicadores

ligados ao programa, por curso

\begin{tabular}{llllll}
\hline Atributos & Contábeis & Direito & Filosofia & $\begin{array}{l}\text { Serviço } \\
\text { Social }\end{array}$ & $\begin{array}{l}\text { Pontuação } \\
\text { geral }\end{array}$ \\
\hline $\begin{array}{l}\text { Número total de estudantes } \\
\text { ativos do curso }\end{array}$ & 100 & 100 & 100 & 70 & 92 \\
\hline $\begin{array}{l}\text { Número de instituições acre- } \\
\text { ditadoras de pós-graduação } \\
\text { pelas quais a instituição de } \\
\text { ensino é acreditada }\end{array}$ & 100 & 0 & 90 & 90 & 56 \\
\hline $\begin{array}{l}\text { Número de horas/aulas que o } \\
\text { programa disponibiliza para }\end{array}$ & 100 & 80 & 90 & 40 & 80 \\
$\begin{array}{l}\text { apoio ou nivelamento dos } \\
\text { novos alunos }\end{array}$ & 100 & 100 & 100 & 80 \\
\hline $\begin{array}{l}\text { Carga horária total do curso } \\
\text { avaliado }\end{array}$ & 100 & 100 & 100 & 70 & 72 \\
\hline $\begin{array}{l}\text { Número de alunos inscritos } \\
\text { no curso no último ano/nú- } \\
\text { mero de vagas oferecidas no } \\
\text { mesmo período }\end{array}$ & 90 & 0 & 0 & 0 & 0 \\
\hline $\begin{array}{l}\text { Número de horas/aulas não } \\
\text { presenciais ofertadas pelo } \\
\text { curso/número total de horas } \\
\text { de aula ofertadas pelo curso }\end{array}$ & 0 & 80 & 100 & 100 & 70 \\
\hline $\begin{array}{l}\text { Número de orientandos } \\
\text { por cada membro do corpo } \\
\text { docente do curso }\end{array}$ & 100 & 84,71 & 67,14 & 64,29 \\
\hline \begin{tabular}{l} 
Pontuação geral \\
\hline
\end{tabular} & & & & \\
\hline
\end{tabular}

Fonte: Dados da pesquisa, 2017.

Um indicador que não recebeu nenhum grau de importância pelos respondentes avalia o número de horas/aulas não presenciais ofertadas pelos cursos. A ausência de valores na mensuração do indicador foi justificada pelos respondentes pelo curso ser totalmente presencial. 
Com isso, identificou-se a satisfação dos respondentes com os indicadores que analisam a qualidade das atividades ofertadas aos seus clientes, compreendendo que a organização das ações analisadas influencia no alcance da excelência do ensino, contribuindo para a valorização da marca da IES perante a sociedade.

A tabela 05 evidencia a cooperação com instituições acadêmicas e não acadêmicas, por curso.

Tabela 05 - Grau de importância de indicadores ligados à cooperação com instituições acadêmicas e não acadêmicas, por curso

\begin{tabular}{|c|c|c|c|c|c|}
\hline Atributos & $\begin{array}{l}\text { Contá- } \\
\text { beis }\end{array}$ & $\begin{array}{l}\text { Di- } \\
\text { reito }\end{array}$ & $\begin{array}{l}\text { Filo- } \\
\text { sofia }\end{array}$ & $\begin{array}{l}\text { Ser- } \\
\text { viço } \\
\text { So- } \\
\text { cial }\end{array}$ & $\begin{array}{l}\text { Pon- } \\
\text { tuação } \\
\text { geral }\end{array}$ \\
\hline $\begin{array}{l}\text { Número de acordos de cooperação (em atividade) } \\
\text { envolvendo o curso e outras instituições acadêmicas } \\
\text { brasileiras }\end{array}$ & 70 & 0 & 70 & 80 & 55 \\
\hline $\begin{array}{l}\text { Número de acordos de cooperação (em atividade) } \\
\text { envolvendo o curso e instituições não acadêmicas ou } \\
\text { empresas parceiras no Brasil }\end{array}$ & 100 & 100 & 100 & 100 & 100 \\
\hline $\begin{array}{l}\text { Número de docentes visitantes de outras universi- } \\
\text { dades (nacionais)/número total de docentes entre } \\
\text { janeiro e dezembro do último exercício social }\end{array}$ & 90 & 0 & 0 & 100 & 47,5 \\
\hline $\begin{array}{l}\text { Número de discentes matriculados no curso que } \\
\text { cursam ou cursaram matérias em outras IES/Número } \\
\text { total de discentes matriculados no curso entre janeiro } \\
\text { e dezembro do último exercício social }\end{array}$ & 10 & 10 & 10 & 10 & 10 \\
\hline $\begin{array}{l}\text { Número de discentes (ativos) do curso frutos de } \\
\text { convênios com entidades não acadêmicas no Brasil/ } \\
\text { número total de discentes do curso }\end{array}$ & 90 & 100 & 0 & 0 & 47,5 \\
\hline $\begin{array}{l}\text { Número de docentes do quadro permanente } \\
\text { do curso que prestaram consultoria remunerada a } \\
\text { entidades não acadêmicas entre janeiro e dezembro } \\
\text { do último exercício social }\end{array}$ & 30 & 30 & 0 & 0 & 15 \\
\hline Pontuação geral & 65 & 40 & 30 & 48,33 & 45,83 \\
\hline
\end{tabular}

Fonte: Dados da pesquisa, 2017. 
A tabela apresenta a importância atribuída à relação construída entre os cursos e os parceiros da IES.

Os acordos mantidos pelas coordenações apontam o desenvolvimento de políticas de estágio para os discentes, contribuindo para a criação, compartilhamento e conversão do conhecimento tácito em explícito dos discentes e da IES, como abordado por Vasconcelos, Castro e Brito (2018), Santos et al. (2017), Brito, Oliveira e Castro (2012) e Nonaka e Takeuchi (1997). A estratégia vai ao encontro das necessidades dos discentes e do Ministério da Educação, pela exigência de uma carga horária mínima vinculada ao estágio profissional, contribuindo para o crescimento profissional dos discentes, e para a visibilidade da marca da IES perante a comunidade.

Os indicadores elucidam que não existe importância em estabelecer discentes frutos de convênio com entidades não acadêmicas no Brasil, e que, com exceção do curso de Ciências Contábeis, as coordenações não atribuem nenhuma importância aos discentes que cursaram matérias em outras instituições, e não acompanham as atividades de consultoria desenvolvidas pelos docentes em outras instituições.

Com isso, identifica-se que as coordenações preocupam-se em construir uma relação harmoniosa com os parceiros que possam favorecer a instituição com políticas de estágio profissional. Todavia, preocupam-se em manter relações apenas com seus clientes diretos, desconsiderando a importância de estabelecer uma comunicação com clientes de outras Instituições que poderiam contribuir com o compartilhamento de novos conhecimentos.

Como visualizado na tabela 06 , os indicadores que buscaram mensurar a importância conferida à internacionalização dos cursos foram as medidas mais fracas.

Analisando a importância do capital do cliente na construção do conhecimento da IES, o modelo se propõe a avaliar a relação desta com outras instituições acadêmicas e não acadêmicas, conforme pode ser visualizado na tabela 07. 
Tabela 07 - Grau de importância de indicadores ligados ao relacionamento com instituições acadêmicas e não acadêmicas, por curso

\begin{tabular}{llllll}
\hline Atributos & Contábeis & Direito & Filosofia & $\begin{array}{l}\text { Serviço } \\
\text { Social }\end{array}$ & $\begin{array}{l}\text { Pontuação } \\
\text { geral }\end{array}$ \\
\hline $\begin{array}{l}\text { Número de palestras realizadas } \\
\text { em eventos não acadêmicos pelos } \\
\text { docentes entre janeiro e dezembro do } \\
\text { último exercício social }\end{array}$ & 30 & 10 & 100 & 80 & 55 \\
\hline $\begin{array}{l}\text { Frequência que a coordenação do } \\
\text { curso promove atividades acadêmicas } \\
\text { para a comunidade }\end{array}$ & 80 & 100 & 100 & 80 & 90 \\
\hline $\begin{array}{l}\text { Número de trabalhos ou palestras } \\
\text { apresentados em eventos acadêmicos } \\
\text { pelos docentes entre janeiro e dezem- } \\
\text { bro do último exercício social }\end{array}$ & 90 & 100 & 50 & 80 & 80 \\
\hline $\begin{array}{l}\text { Número de horas que foram gastas } \\
\text { pelos docentes } \\
\text { em atividades } \\
\text { extracurriculares entre janeiro e } \\
\text { dezembro do último exercício social }\end{array}$ & 70 & 80 & 0 & 0 & 37,5 \\
\hline $\begin{array}{l}\text { Número de revistas indexadas cujo } \\
\text { corpo de editores possua, pelo me- } \\
\text { nos, um membro do curso }\end{array}$ & 0 & 0 & 30 & 0 & 7,5 \\
\hline $\begin{array}{l}\text { Número de acessos ao site do curso } \\
\text { na internet entre janeiro e dezembro } \\
\text { do último exercício social }\end{array}$ & 70 & 70 & 70 & 0 & 52,5 \\
\hline \begin{tabular}{l} 
Pontuação geral \\
\hline
\end{tabular} & 56,67 & 60 & 58,33 & 40 & 53,75 \\
\hline
\end{tabular}

Fonte: Dados da pesquisa, 2017.

Quanto aos indicadores que mensuram o relacionamento da IES com outras instituições acadêmicas e não acadêmicas, os atributos mostram que existe uma percepção acerca do retorno institucional por intermédio desta relação.

Autores como Al-hemyari e Al-sarmi (2018), Bratianu (2018), Cricelli et al. (2018), Ndou et al. (2018), Stewart (1998), Sveiby (1998) e Nonaka e Takeuchi (1997), defendem a posição de que os gestores precisam conhecer seus clientes e saber como servi-los. Desta forma, 
os coordenadores, dentro de suas atribuições e formalização do conhecimento, oferecem atendimento à comunidade, o que viabiliza o aperfeiçoamento e o crescimento do conhecimento, definido por Neves et al. (2018) e Sveiby (1998) como sendo um ativo que não sofre depreciação, e aumenta ao ser compartilhado. Além disso, as parcerias com a comunidade estabelecem com a IES uma rede de contatos com a sociedade.

Os trabalhos apresentados em eventos acadêmicos pelos docentes interagem como ação estratégica pela conversão em conhecimento explícito, e pela divulgação do curso junto a outras instituições brasileiras. Entretanto, as coordenações não se utilizam de práticas para favorecer o conhecimento a nível individual.

Os indicadores número de horas/aulas gastas com atividades extracurriculares, número de revistas indexadas, e os acessos realizados ao site do curso na internet, foram descritos pelos coordenadores como atividades que a coordenação não mantém o controle.

$\mathrm{Na}$ análise da dimensão do capital do cliente foi constatado que a IES possui ações conectadas com a criação e a disseminação do conhecimento, e que existe um relacionamento satisfatório entre os clientes e a instituição pela preocupação das coordenações em estabelecê-lo com outros clientes e fornecedores de estágios para os discentes, permitindo a interação do conhecimento tácito e o explícito, além de favorecer a comunidade com os serviços dos estudantes. Entretanto, a ausência de ações estratégicas pode influenciar na perda de competitividade. Para Cricelli et al. (2018) e Davel e Souza (2004), as organizações do conhecimento precisam combinar o capital humano com as tecnologias disponíveis para garantir a organização e aumento da produtividade.

\subsection{Importância do Capital Humano}

A terceira dimensão avaliada é o capital humano que compreende as expertises, inteligência, criatividade e valores dos trabalhadores que fornecem serviço à organização (STEWART, 1998). A tabela 08 analisará os ativos intangíveis ligados aos docentes, por curso. 
Tabela 08 - Grau de importância de indicadores ligados aos docentes, por curso

\begin{tabular}{llllll}
\hline Atributos & Contábeis & Direito & Filosofia & $\begin{array}{l}\text { Serviço } \\
\text { Social }\end{array}$ & $\begin{array}{l}\text { Pon- } \\
\text { tuação } \\
\text { geral }\end{array}$ \\
\hline $\begin{array}{l}\text { Distribuição dos docentes do curso de } \\
\text { administração por linha de pesquisa }\end{array}$ & 40 & 70 & 100 & 50 & 65 \\
\hline $\begin{array}{l}\text { Número total de horas de trabalho de- } \\
\text { dicadas pelos docentes à pesquisa entre } \\
\text { janeiro e dezembro do último exercício }\end{array}$ & 50 & 50 & 0 & 37,5 \\
social & & & & & \\
\hline $\begin{array}{l}\text { Número total de horas de trabalho de- } \\
\text { dicadas pelos docentes em sala de aula, } \\
\text { entre janeiro e dezembro do último } \\
\text { exercício social }\end{array}$ & 100 & 100 & 100 & 100 & 100 \\
\hline $\begin{array}{l}\text { Histograma com os anos de experiência } \\
\text { não acadêmica, por docente do curso }\end{array}$ & 30 & 50 & 0 & 30 & 27,5 \\
\hline $\begin{array}{l}\text { Número de docentes com dedicação } \\
\text { exclusiva/número total de docentes do } \\
\text { curso }\end{array}$ & 40 & 0 & 0 & 0 & 10 \\
\hline $\begin{array}{l}\text { Histograma com o número de participa- } \\
\text { ções em grupos de pesquisa, por } \\
\text { cada membro do corpo docente } \\
\text { do curso, considerando-se apenas aque- } \\
\text { les aderentes às respectivas linhas de } \\
\text { pesquisa }\end{array}$ & 50 & 20 & 0 & 25 \\
\hline \begin{tabular}{l} 
Pontuação geral \\
\hline
\end{tabular} & 58,33 & 53,33 & 45 & 30 & 44,17 \\
\hline
\end{tabular}

Fonte: Dados da pesquisa, 2017.

Esses indicadores apontam nitidamente a relação contratual da IES com o capital humano (docentes), que é integralmente avaliada pelo número de horas dedicadas em sala de aula.

Os entrevistados não possuem nenhum controle sobre as ações interligadas à produção científica. No discurso dos gestores identificou-se o reconhecimento da importância dos profissionais como principal ativo existente, concordando com Dumay (2009a) e diversos outros autores como Neves et al. (2018), Sardo, Serrasqueiro e 
Alves (2018), Nadeem, Gan e Nguyen (2018) e Novgorodov (2018), ao reconhecer as pessoas como o maior patrimônio de uma Instituição. Entretanto, os projetos de pesquisa e as atividades de extensão competem a um departamento específico da IES: NEPA.

Os coordenadores relataram que a IES disponibiliza ajuda financeira para os profissionais que participam de eventos acadêmicos, mas que estes resultados não são apresentados na criação de valor da IES. O recurso é estendido a programas de qualificação profissional, onde a direção prioriza os investimentos, por ser uma exigência imposta pelo MEC em manter um percentual de mestres e doutores, e por uma necessidade dos clientes. Todavia, os docentes buscam o auxílio junto à direção da IES, a qual estabelece as formas que pode contribuir, sem que haja o envolvimento das coordenações.

As ações desenvolvidas demonstram a valorização atribuída ao capital humano na gestão da IES, e que existe a priorização de investimentos em projetos de pesquisa e extensão, incentivos a participações em congressos e eventos acadêmicos, além de contribuir com ajuda financeira para qualificação profissional. A IES percebe a importância de manter profissionais qualificados, entretanto, o que se nota é que não existem indicadores de controle acerca do retorno institucional, a partir da exposição dos resultados alcançados, por meio de ações vinculadas à competência dos profissionais.

Outro ativo intangível crítico diz respeito ao pessoal administrativo, conforme observa-se na tabela 09.

$\mathrm{O}$ indicador que analisa o número de pessoas que deixaram de fazer parte do quadro de funcionários, tratado por Sveiby (1998) como um indicador de estabilidade na avaliação da competência das pessoas, possibilitou identificar que a taxa de rotatividade destes profissionais é zero, ou seja, os profissionais executam as suas atividades no cargo desde a abertura do curso, com exceção do curso de Ciências Contábeis.

Observa-se que os indicadores avaliam apenas a carga horária, investimentos em capacitação, e histograma de tempo que os profissionais exercem a atividade, sem analisar como estas atividades estão acrescentando valor à organização. Nadeem, Gan e Nguyen (2018) e Stewart (1998) dizem que os profissionais que não agregam valor à organização não podem ser referenciados como capital hu- 
mano. Diante disso, observa-se que uma das limitações atribuídas ao modelo é a existência de indicadores insuficientes para analisar a contribuição destes funcionários, informações sobre atitudes, inovações, eficiência medida através da experiência, satisfação na qualidade do atendimento que prestam aos clientes, ou como agregam valor ao curso.

Tabela 09 - Grau de importância de indicadores

ligados ao pessoal administrativo, por curso

\begin{tabular}{|c|c|c|c|c|c|}
\hline Atributos & Contábeis & $\begin{array}{l}\text { Direi- } \\
\text { to }\end{array}$ & $\begin{array}{l}\text { Filoso- } \\
\text { fia }\end{array}$ & $\begin{array}{l}\text { Ser- } \\
\text { viço } \\
\text { Social }\end{array}$ & $\begin{array}{l}\text { Pon- } \\
\text { tuação } \\
\text { geral }\end{array}$ \\
\hline $\begin{array}{l}\text { Carga horária total dos funcio- } \\
\text { nários que se dedicam diretamente ao } \\
\text { curso }\end{array}$ & 100 & 100 & 80 & 100 & 95 \\
\hline $\begin{array}{l}\text { Investimento (horas) na capacitação de } \\
\text { funcionários do curso/número de funcio- } \\
\text { nários do curso entre janeiro e dezembro } \\
\text { do último exercício social }\end{array}$ & 100 & 80 & 70 & 50 & 75 \\
\hline $\begin{array}{l}\text { Histograma com o tempo (anos) que cada } \\
\text { funcionário administrativo exerce sua } \\
\text { atividade no curso }\end{array}$ & 70 & 100 & 100 & 100 & 92,5 \\
\hline $\begin{array}{l}\text { Número de pessoas que deixaram de } \\
\text { fazer parte do quadro de funcionários/nú- } \\
\text { mero total de funcionários do curso entre } \\
\text { janeiro e dezembro do último exercício } \\
\text { social }\end{array}$ & 80 & 100 & 100 & 100 & 95 \\
\hline Pontuação geral & 87,5 & 95 & 87,5 & 87,5 & 89,38 \\
\hline
\end{tabular}

Fonte: Dados da pesquisa, 2017.

Entretanto, observa-se que a IES oferece um ambiente propício à valorização do capital humano, visto que os respondentes reconhecem a importância dos profissionais para o desenvolvimento da Instituição. Todavia não vincula os investimentos disponibilizados às coordenações, ou seja, o recurso é disponibilizado mediante a procura pelo profissional. 
A tabela 10 mostra a contribuição da coordenação na composição do atributo capital humano.

Tabela 10 - Grau de importância de indicadores

ligados à coordenação, por curso

\begin{tabular}{llllll}
\hline Atributos & Contábeis & Direito & Filosofia & $\begin{array}{l}\text { Serviço } \\
\text { Social }\end{array}$ & $\begin{array}{l}\text { Pon- } \\
\text { tuação } \\
\text { geral }\end{array}$ \\
\hline $\begin{array}{l}\text { Tempo total acumulado (anos) que o } \\
\text { coordenador do curso exerce(u) função } \\
\text { executiva/direção em instituição acadêmica }\end{array}$ & 80 & 100 & 80 & 100 & 95 \\
\hline $\begin{array}{l}\text { Tempo (em anos) que o coordenador exerce } \\
\text { seu cargo dentro do curso }\end{array}$ & 100 & 100 & 100 & 90 & 97,5 \\
\hline $\begin{array}{l}\text { Número de eventos acadêmicos - congres- } \\
\text { sos, visitas técnicas, palestras etc. - dos } \\
\text { quais o coordenador (ou membros da coor- } \\
\text { denação), tenha participado como represen- } \\
\text { tante do curso, entre janeiro e dezembro do } \\
\text { último exercício social }\end{array}$ & 60 & 100 & 80 & 75 \\
\hline \begin{tabular}{l} 
Pontuação geral \\
\hline
\end{tabular} & 80 & 86,67 & 100 & 90 & 89,17 \\
\hline
\end{tabular}

Fonte: Dados da pesquisa, 2017.

A análise dos indicadores evidenciou que os coordenadores já executaram outras atividades, e que já acompanham as coordenações há algum tempo. No caso da coordenação de Ciências Contábeis, a coordenadora exerce a função desde a abertura do curso na IES. Um indicador apresentado como ponto fraco para as coordenações de Ciências Contábeis e Direito é o número de participações em eventos e congressos que participaram como representantes do curso. À esta prerrogativa a coordenadora de Direito justificou que começou a exercer a função no período pesquisado, e que sua formação não é em ciências jurídicas. Os demais cursos apresentam-se satisfeitos com os investimentos realizados pela instituição no que tange à sua qualificação profissional.

Através da análise dos ativos intangíveis evidenciou-se que a instituição investe em qualificação profissional por meio de recursos financeiros destinados aos docentes, técnicos e coordenadores. Entretanto, se faz necessário rever as políticas da instituição e vincular os recursos disponibilizados às coordenações, para que 
os coordenadores responsáveis conectem os investimentos com a criação e disseminação de novos conhecimentos.

Em alguns casos houve respostas diferentes entre os gestores, mas a similaridade entre estas foi apresentada pela maioria, como pode se confirmar na tabela 11.

Tabela 11 - Estatística descritiva do nível de importância e dificuldade das dimensões

\begin{tabular}{|c|c|c|c|c|c|c|}
\hline Ativos Intangíveis Críticos & $\begin{array}{l}\text { Míni- } \\
\text { mo }\end{array}$ & $\begin{array}{l}\text { Máxi- } \\
\text { mo }\end{array}$ & $\begin{array}{l}\text { Me- } \\
\text { diana }\end{array}$ & $\begin{array}{l}\text { Mé- } \\
\text { dia }\end{array}$ & $\begin{array}{l}\text { Des- } \\
\text { vio }\end{array}$ & $\begin{array}{l}\text { P - } \\
\text { Valor }\end{array}$ \\
\hline \multicolumn{7}{|l|}{ Importância } \\
\hline Gestão de controle & 60 & 100 & 80 & 80 & 15,81 & \multirow{10}{*}{0,516} \\
\hline Pesquisa e produção intelectual & 0 & 100 & 50 & 58 & 39,62 & \\
\hline Infraestrutura & 10 & 100 & 80 & 70 & 35,36 & \\
\hline O programa & 50 & 100 & 70 & 74 & 18,17 & \\
\hline $\begin{array}{l}\text { Cooperação com instituições acadêmicas e } \\
\text { não acadêmicas }\end{array}$ & 20 & 100 & 70 & 70 & 30,82 & \\
\hline Internacionalização & 0 & 80 & 10 & 28 & 35,64 & \\
\hline $\begin{array}{l}\text { Relacionamento com instituições acadêmicas } \\
\text { e não acadêmicas }\end{array}$ & 20 & 100 & 70 & 66 & 29,66 & \\
\hline Docentes & 10 & 90 & 70 & 78 & 30,33 & \\
\hline Pessoal administrativo & 0 & 100 & 80 & 70 & 41,23 & \\
\hline Coordenação & 10 & 100 & 90 & 74 & 37,82 & \\
\hline \multicolumn{7}{|l|}{ Dificuldade } \\
\hline Gestão de controle & 0 & 61,67 & 23,33 & 26,67 & 27,26 & \multirow{10}{*}{0,915} \\
\hline Pesquisa e produção intelectual & 0 & 86,67 & 11,67 & 23 & 36,33 & \\
\hline Infraestrutura & 0 & 60 & 28 & 24 & 25,14 & \\
\hline O programa & 0 & 78,57 & 7,14 & 20,86 & 32,8 & \\
\hline $\begin{array}{l}\text { Cooperação com instituiç̧ões acadêmicas e } \\
\text { não acadêmicas }\end{array}$ & 0 & 86,67 & 0 & 20 & 37,71 & \\
\hline Internacionalização & 0 & 100 & 0 & 20 & 44,72 & \\
\hline $\begin{array}{l}\text { Relacionamento com instituições acadêmicas } \\
\text { e não acadêmicas }\end{array}$ & 0 & 61,67 & 5 & 16 & 26,1 & \\
\hline Docentes & 0 & 100 & 15 & 27 & 41,77 & \\
\hline Pessoal administrativo & 0 & 100 & 5 & 23,5 & 43,07 & \\
\hline Coordenação & 0 & 100 & 33,33 & 39,33 & 42,97 & \\
\hline
\end{tabular}

Fonte: Dados da pesquisa, 2017. 
A veracidade dos dados é evidenciada através do teste de Kruskal Wallis. Considerando um nível de significância de 5\%, têm-se evidências que não existe diferença estatística significante quanto ao grau de importância e desempenho entre as 10 dimensões estudadas, classificando a análise como descritiva. Em relação à interpretação sobre recomendações, quanto aos atributos estudados, a figura 01 demonstra a importância atribuída.

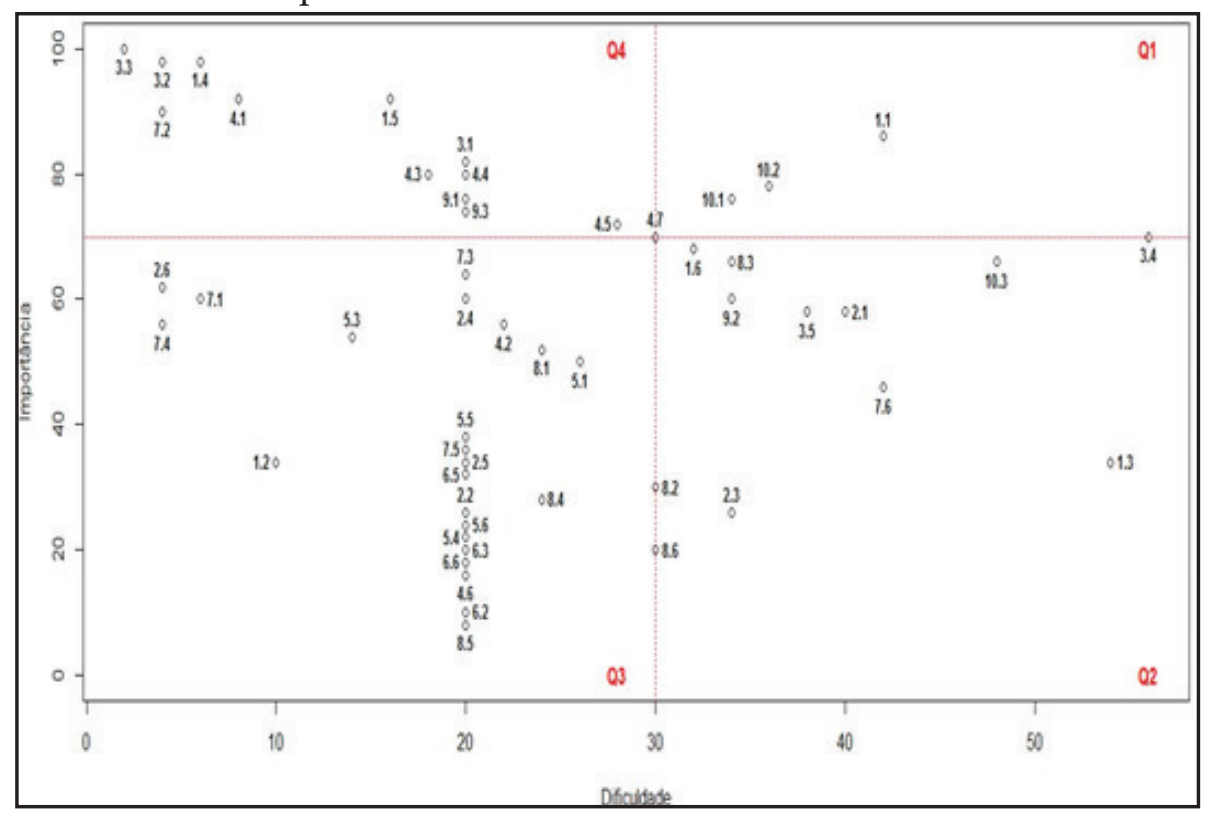

Figura 01 - Matriz de importância e dificuldade

Fonte: Dados da pesquisa, 2017.

Empregou-se a ferramenta de matriz de importância e dificuldade, tendo como ponto de corte para separação dos quadrantes mediana de 70 pontos para o quesito "importância", e mediana de 30 pontos para o quesito "dificuldade". Desse modo, tem-se a seguinte classificação: indicadores elegíveis (Q4); relevância na opinião dos professores e coordenadores consultados (Q3); alta dificuldade para serem elaborados (Q1); ou, ambos os casos (Q2).

A análise consiste na interpretação dos indicadores analisados, reconhecendo-se que a mediana de 70 representa os indicadores considerados na avaliação do CI pelos coordenadores. 


\section{CONSIDERAÇõES FINAIS}

$\mathrm{Na}$ análise da dimensão capital estrutural, identificou-se que a IES prioriza os investimentos nessa área, entretanto, as ações podem não contribuir com o seu CI, pois os gestores não se utilizam dos investimentos efetuados para criar e favorecer novos conhecimentos. A ausência de controle do número de publicações dos docentes, bem como os investimentos destinados à qualificação profissional sem nenhum direcionamento à produção de novos conhecimentos, e a importância atribuída ao número de horas/aulas prestadas pelos docentes permitem inferir que, como uma organização do conhecimento, pouca importância vem sendo atribuída pelos gestores à dimensão analisada.

Na análise da dimensão capital do cliente identificou-se que existe um relacionamento satisfatório entre os clientes e a instituição pela preocupação das coordenações em estabelecer com outros clientes e fornecedores programas de estágios direcionados aos discentes, contribuindo com a transformação do conhecimento tácito em explícito, além de favorecer a comunidade com os serviços realizados pelos estudantes.

$\mathrm{Na}$ análise dos ativos intangíveis percebeu-se que as coordenações não divulgam os resultados das atividades desenvolvidas pelos docentes e discentes, e que estas poderiam contribuir com o reconhecimento do curso. Deste modo, os coordenadores reconhecem a valorização dos clientes, entretanto a ausência de ações que contribuam com o crescimento dos ativos intangíveis vem implicando em perda de clientes.

Em relação à dimensão capital humano da IES, evidenciou-se que há investimento em qualificação profissional por meio de recursos financeiros destinados aos docentes, técnicos e coordenadores. Entretanto, se faz necessário rever as políticas da instituição e vincular os recursos disponibilizados às coordenações para que os coordenadores responsáveis conectem os investimentos com a criação e disseminação de novos conhecimentos.

Respondendo ao objetivo norteador desta pesquisa, constatou-se que há importância atribuída aos ativos intangíveis críticos em todas as dimensões no processo avaliativo, mas a falta de gerenciamento destes ativos de forma eficiente reflete na composição do CI da IES. 
O que se percebe é que as gestões ainda desenvolvem suas atividades sem uma devida orientação estratégica ou compreensão que o gerenciamento destas ações implica na criação da imagem da IES, e na valorização dos cursos perante a sociedade.

Foi possível identificar que a falta de direcionamento estratégico aos ativos físicos (capital estrutural) implica no desenvolvimento das demais dimensões - capital do cliente e capital humano -, por serem os ativos pertencentes à IES, e que devem auxiliar o crescimento destas dimensões, o que implica dizer que se não existe uma orientação estratégica direcionada às ações desenvolvidas, a instituição perderá uma fatia de mercado e não aproveitará as competências, habilidades, e conhecimento de seus empregados, como observado por Stewart (1998).

Além das considerações apresentadas, recomenda-se o desenvolvimento de uma nova pesquisa, confrontando a opinião da instituição com a dos docentes, funcionários e clientes, além da aplicação em outras IES para possíveis comparações com os resultados aqui encontrados.

\section{Agradecimentos}

O presente trabalho foi realizado com apoio da Coordenação de Aperfeiçoamento de Pessoal de Nível Superior - Brasil (CAPES) - Código de Financiamento 001.

\section{REFERÊNCIAS}

ACEVEDO, C. R.; NOHARA, J. J. Monografia no curso de administração: guia completo de conteúdo e forma. 2. ed. São Paulo: Atlas, 2006.

BODNÁR, V.; HARANGOZÓ, T.; TIRNITZ, T.; RÉVÉSZ, É.; KOVÁTS, G. Managing intellectual capital in Hungarian Universities: the case of Corvinus University of Budapest. In: European Conference on Intellectual Capital, 2., 2010, Lisboa. Anais... Lisboa: ECIC, 2010. p. 89-99.

AL-HEMYARI, Z. A.; AL-SARMI, A. M. Information Management Model for Intellectual Capital of HEIs in Oman: Theoretical Quantitative Approach and Practical Results. Journal of Information \& Knowledge Management, v. 17, n. 1, p. 185-195, 2018.

BRATIANU, C. A. Critical analysis of intellectual capital research in universities. Proceedings of the International Conference on Business Excellence, v. 12, n. 1, p. 151-160. 2018.

BRITO, L. M. P.; OLIVEIRA, P. W. S. de; CASTRO, A. B. C. de. Gestão do conhecimento numa instituição pública de assistência técnica e extensão rural do Nordeste do Brasil. Revista de Administração Pública, v. 46, n. 5, p. 1341-1366, 2012. 
BROOKING, A. Intellectual capital: core asset for the third millennium enterprise. Boston: Thomson Publishing Inc, 1996. 224 p.

CASTRO, A. B. C.; BRITO, L. M. P.; VARELA, J. H. S. A ressignificação da área de gestão de pessoas e os novos papéis das pessoas e das organizações. HOLOS, v. 4, p. 408-423, 2017.

CERVO, A. L.; BERVIAN, P. A.; SILVA, R. Metodologia Cientifica. 6. ed. São Paulo: Pearson Education do Brasil, 2007. 176 p.

CRICELLI, L.; GRECO, M.; GRIMALDI, M.; DUENAS, L. P. L. Capital intelectual e desempenho universitário em países emergentes: evidências de universidades públicas colombianas. Journal of Intellectual Capital , v. 19, n. 1, p. 71-95, 2018.

DAVEL, E.; SOUZA, J. Aprendizado e formação continuada em organizações familiares e intensivas em conhecimento: a força das relações de parentesco por consideração. In: ENEO, 3., 2004, Atibaia. Anais... Atibaia, 2004.

DUMAY, J. C. Intellectual capital measurement: a critical approach. JIC, v. 10, n. 2, p. 190210, 2009a.

DUMAY, J. C. Reflective discourse about intellectual capital: research and practice. JIC, v. 10, n. 4, p. 489-503, 2009b.

EDVINSSON, L.; MALONE, M. S. Capital intelectual: descobrindo o valor real de sua empresa pela identificação de seus valores internos. São Paulo: Makron Books, 1998.

GIL, A. C. Métodos e técnicas de pesquisa social. 6. ed. São Paulo: Atlas, 2008.

KLEIN, D. A. A gestão estratégica do capital intelectual: recursos para a economia baseada em conhecimento. Rio de Janeiro: Qualitymark, 1998. 360 p.

KOCH, G.; LEITNER, K.; BORNEMANN, M. Measuring and reporting intangible assets and results in a European Contract Research Organization. In: Joint German-OECD Conference: benchmarking industry-science relationships, 2000, Berlin. Anais... Berlin, 2000.

LEITNER, K. Intellectual capital reporting for universities: conceptual background and application for Austrian universities. Research Evaluation, v. 13, n. 2. p. 129-140, ago. 2004.

MARQUES, M. C. C. A problemática da medição do capital intelectual nas organizações da sociedade do conhecimento. RBC, n. 178/179/180, p. 25-36, 2009.

MARR, B.; GRAY, D.; NEELY, A. Why do firms measure their intellectual capital? JIC, v. 4, n. 4, p. 441-464, 2003.

MOURITSEN, J. Intellectual capital and the capital market: the circulability of intellectual capital. Accounting, Auditing e Accountability Journal, v. 16, n. 1, p. 18-30, 2003.

NADEEM, M.; GAN, C.; NGUYEN, C. The Importance of Intellectual Capital for Firm Performance: Evidence from Australia. Australian Accounting Review, v. 28, n. 3, p. 334-344, 2018.

NAIR, P.; PRAKASH, K. Knowledge Management: Facilitators Guide. Tokyo: APO, 2009. 756 p.

NDOU, V.; SECUNDO, G.; DUMAY, J.; GJEVORI, E. Understanding intellectual capital disclosure in online media Big Data: An exploratory case study in a university. Meditari Accountancy Research, v. 26, n. 3, p. 499-530, 2018. 
NEVES, F. R.; FARIAS, R. S.; SANTANA, N. G.; CARVALHO, C. A. S. V. Intangibilidade do capital intelectual na prática dos escritórios de contabilidade. Revista Ambiente Contábil, v. 10, n. 2, p. 248-265, 2018.

NONAKA, I.; TAKEUCHI, H. Criação de conhecimento na empresa: como as empresas japonesas geram a dinâmica da inovação. Trad. Ana Beatriz Rodrigues e Priscilla Martins Celeste. 20. ed. Rio de Janeiro: Elsevier, 1997. 340 p.

NOVGORODOV P. A. Efficiency of universities performance: From monitoring and ranking to intellectual capital evaluation. Upravlenets - The Manager, v. 9, n. 1, p. 48-55, 2018.

REZENDE, Yara. Informação para negócios: os novos agentes do conhecimento e a gestão do capital intelectual. Ciência da Informação, v. 31, n. 1, p. 75-83, 2002.

SÁNCHEZ, P.; CHAMINADE, C.; OLEA, M. Management of intangibles. An attempt to build a theory. JIC, v. 1, n. 4, p. 312-327, 2000.

SANTOS, R. S.; CASTRO, A. B. C.; FARIAS, M. S. B.; BRITO, L. M. P. Organizações de aprendizagem: disciplinas para a gestão com pessoas no serviço público. Holos, v. 8, p. 205-228, 2017.

SARDO, F.; SERRASQUEIRO, Z.; ALVES, H. On the relationship between intellectual capital and financial performance: A panel data analysis on SME hotels. International Journal of Hospitality Management, v. 75, p. 67-74, 2018.

STEWART, T. A. Capital intelectual: a nova vantagem competitiva das empresas. 2. ed. Rio de Janeiro: Campus, 1998.

SVEIBY, K. E. A nova riqueza das organizações: gerenciando e avaliando patrimônios de conhecimento. Trad. Luiz Euclydes Trindade Frazão Filho. 7. ed. Rio de Janeiro: Campus, 1998. 280 p.

TERRA, J. C. C. Gestão do Conhecimento: o grande desafio empresarial. 5. ed. Rio de Janeiro: Elsevier, 2005. 315 p.

VASCONCELOS, C. R. M.; CASTRO, A. B. C.; BRITO, L. M. P. Gestión del conocimiento e innovación. Pensamiento y Gestion, v. 2, p. 97-128, 2018.

VERGARA, S. C. Projetos e relatórios de pesquisa em administração. 15. ed. São Paulo: Atlas, 2014.

Recebido em: 20-01-2021

Aprovado em: 3-12-2021

Avaliado pelo sistema double blind review.

Disponível em http://mjs.metodista.br/index.php/roc 